\title{
Tendencias del turismo residencial: El caso del Mediterráneo Español
}

\author{
Raquel Huete Nieves
}

\author{
RESUMEN
}

En las últimas cuatro décadas, la construcción de viviendas para uso turístico ha seguido un ritmo exponencial en el litoral Mediterráneo español. La provincia de Alicante, conocida como Costa Blanca, se ha convertido en uno de los destinos turístico-residenciales más importantes de Europa. En este trabajo se presentan las características básicas de esta oferta de alojamiento privado y se perfilan los rasgos esenciales de la demanda, fundamentalmente pensionistas procedentes de Europa occidental. Por último, se exponen las principales conclusiones que, desde la experiencia alicantina, se han extraído sobre las repercusiones sociales y económicas de este modelo de desarrollo turístico. También se plantean algunas propuestas para una adecuada planificación de esta tipología turística en destinos que podrían seguir un esquema similar.

$$
\text { PALABRAS CLAVE }
$$

Alicante, España, turismo residencial, sustentabilidad, demanda turística. 


\title{
Tendencias del turismo residencial: El caso del Mediterráneo Español
}

\author{
Raquel Huete Nieves
}

\begin{abstract}
Over the last four decades, the construction of second homes for tourists on Spain's Mediterranean coast has grown exponentially. The province of Alicante, known as Costa Blanca, has become one of the most important destinations of residential tourism in Europe. This paper describes the main characteristics of this offer of private accommodation and outlines the main features of its demand, mostly retirees from Western Europe. Finally, it puts forward the main conclusions drawn from Alicante's experience about the social and economic impacts of this tourism development model. The paper also makes some suggestions for an adequate planning of the model in areas that might follow a similar trend.
\end{abstract}

\section{KEY WORDS}

Alicante, Spain, residential tourism, sustainability, tourism demand 


\section{EL TURISMO RESIDENCIAL}

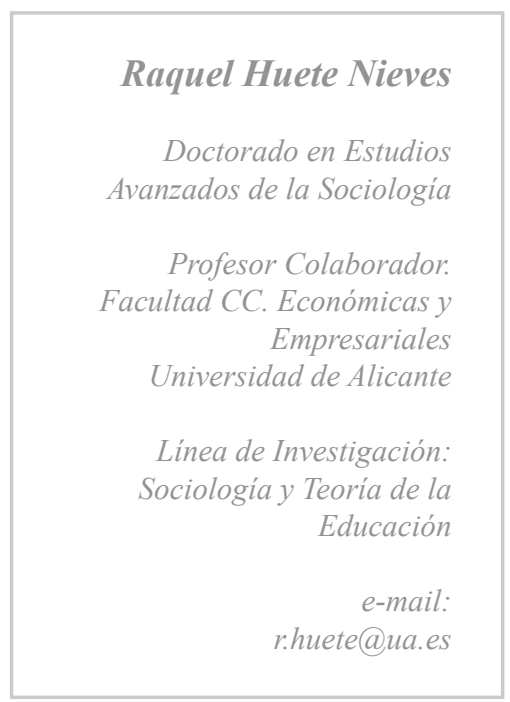

Las profundas transformaciones en las que se hallan inmersas las sociedades occidentales modernas están incidiendo sobremanera en los estilos de vida de sus ciudadanos. El envejecimiento de la población ligado a un aumento de la esperanza de vida, la incorporación de la mujer al mercado de trabajo, las nuevas estructuras familiares, los intensos procesos de urbanización, la reducción del tiempo de trabajo, el acortamiento de la vida laboral, los continuos avances tecnológicos, la globalización de la economía y la sociedad de la información, el abaratamiento de los medios de transporte, son algunos de los factores que están transformando las vidas cotidianas de las personas que integran las llamadas sociedades post-industriales. El resultado es el aumento del tiempo libre y de ocio, unas nuevas pautas de consumo, una mayor atención a la salud y al cuidado personal y la búsqueda de entornos de mejor calidad. En estas sociedades cientos de miles de europeos han escogido las localidades costeras españolas, tanto peninsulares como insulares, como zonas preferidas para la adquisición de una vivienda con fines turísticos, de ocio o bien para establecerse de forma permanente o semipermanente y pasar los años de su jubilación disfrutando de una mejor calidad de vida. Esta forma de movilidad, entre el turismo y la migración, ha dado lugar a un modelo de desarrollo que se ha denominado turismo residencial, cuyas repercusiones económicas, urbanísticas, culturales, políticas y demográficas en las estructuras físicas y sociales de las regiones costeras de muchos lugares del mundo son incuestionables (Hall y Müller; 2004).

Como aproximación al concepto de turismo residencial, se puede considerar, para el propósito de este trabajo, la referencia del informe sobre esta tipología turística en Andalucía que dirigió Pedro Raya: "en un sentido intuitivo (el turismo residencial) alude a una tipología de turistas que utilizan, con mayor frecuencia, alojamientos no reglados y cuyas estancias son relativamente mayores que las del turismo vacacional" (Raya; 2001: 494). Desde la experiencia mexicana, Daniel Hiernaux-Nicolás propone que "el turismo de 
segundas residencias es aquel por el cual las personas acuden a un destino o una localidad que no es forzosamente turísticas per se, donde tienen la posesión por compra, renta o préstamo de un inmueble en el cual pernoctan y realizan actividades de ocio y esparcimiento" (Hiernaux-Nicolás; 2005). Hay una línea de investigación que subraya el proceso urbanizador que se produce: el denominado genéricamente turismo residencial se ha asimilado a la promoción inmobiliaria y a la venta de viviendas, tanto en conjuntos residenciales (urbanizaciones particulares) como en ensanches de núcleos urbanos tradicionales, para acoger a una demanda en continuo crecimiento. Los profesores Tomás Mazón y Antonio Aledo, situados en esta orientación teórica, definen el turismo residencial como "la actividad económica que se dedica a la urbanización, construcción y venta de viviendas que conforman el sector extrahotelero, cuyos usuarios las utilizan como alojamiento para veranear o residir, de forma permanente o semipermanente, fuera de sus lugares de residencia habitual, y que responden a nuevas fórmulas de movilidad y residencialidad de las sociedades avanzadas" (Mazón y Aledo; 2005: 18-19).

El modelo de desarrollo centrado en el turismo residencial se encuentra presente, de forma preeminente, en todas las comunidades del litoral mediterráneo español, así como en las islas Baleares y Canarias (Salvà; 2005; Zapata; 2002). En estas regiones el crecimiento de la vivienda secundaria (1) es espectacular, sobre todo a partir de la década de los 70 . En este escenario, destaca la zona litoral de la Comunidad Valenciana, en particular, la provincia de Alicante (conocida como Costa Blanca en el ámbito turístico), con 482.919 viviendas secundarias, cifra que aglutina al $48,1 \%$ del total de viviendas de esta comunidad autónoma según el último censo disponible (2) (INE; 2001). 


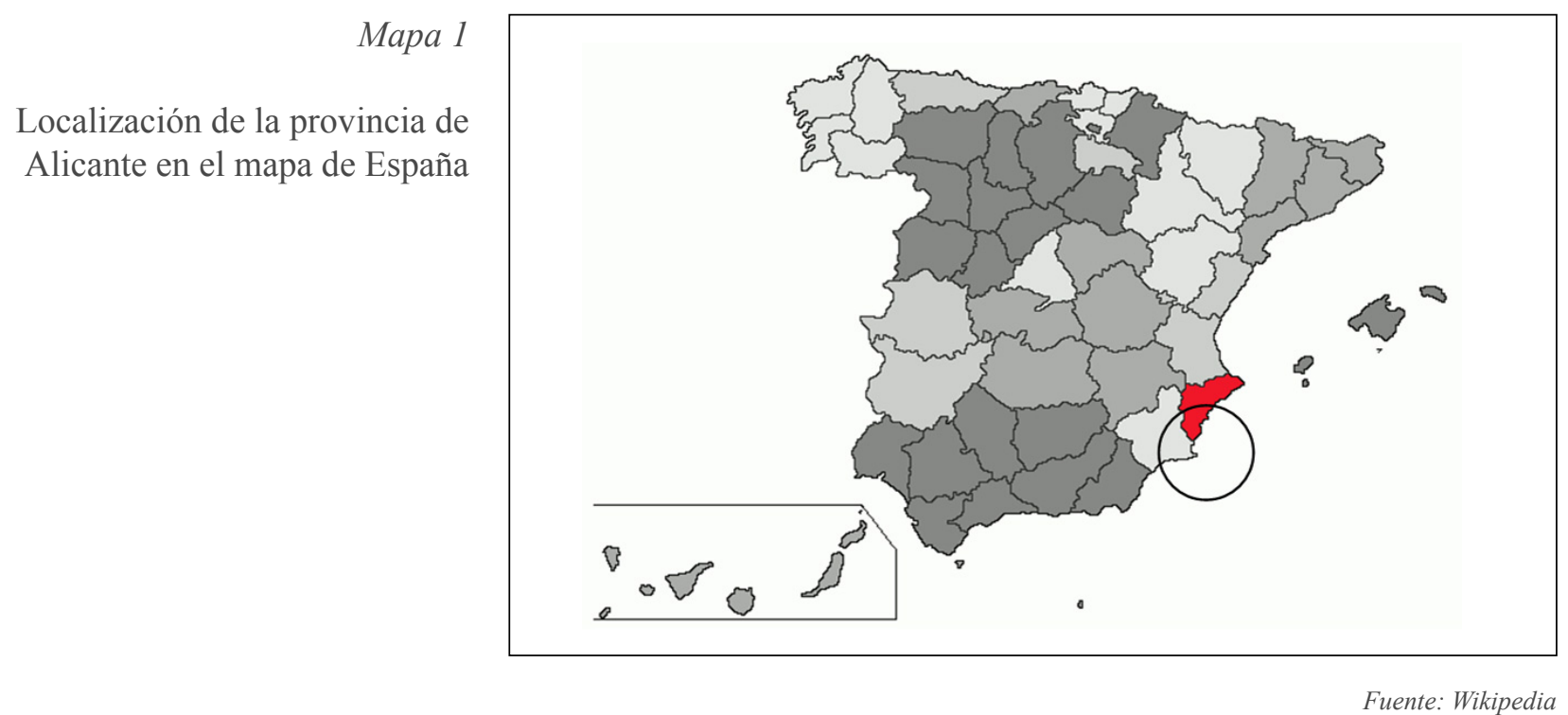

La Comunidad Valenciana, uno de los principales destinos turísticos de España, ha seguido el siguiente proceso en cuanto a su configuración como destino turístico consolidado: una primera fase de incorporación de determinados municipios como centros de veraneo, una segunda de incipientes centros turísticos, una tercera fase en la que se combina la función turística y la residencial, y una última fase en la que se ha entrado tras la superación de la crisis turística de 1989 a 1993, con la hegemonía del turismo residencial (Vera Rebollo y Monfort Mir, 1994). Así, la expansión territorial del sector turístico residencial en la provincia de Alicante se ha desarrollado en tres fases: en primer lugar, a partir de los años 60 , se ocuparon grandes espacios en los municipios costeros, aprovechando el recurso del mar; posteriormente, a comienzos de los 80 , el proceso se extendió a municipios distantes entre 5 y 20 kilómetros de la costa, a causa de la fuerte demanda y del menor coste del suelo; por último, desde finales de los años 90, y sobre todo en los últimos cinco años, la urbanización se extiende a espacios y comarcas del interior que, tradicionalmente, se habían mantenido al margen del proceso inmobiliario, lo que ha dado lugar a nuevos escenarios para este modelo de desarrollo. 


\section{LA DEMANDA TURÍSTICO-RESIDENCIAL}

La demanda de las viviendas para uso residencial proviene, en primer lugar, del mercado nacional, tanto de zonas próximas como de otras comunidades autónomas, ya que el desarrollo económico experimentado por la sociedad española en las últimas dos décadas ha posibilitado la compra de una segunda vivienda a un segmento importante de la población. En segundo lugar, en mayor número cada año, los compradores o arrendatarios de estas segundas residencias son europeos procedentes principalmente de Reino Unido y Alemania, que pasan largas temporadas en España o incluso se trasladan definitivamente. Estos últimos serán el objeto de nuestra atención. Se trata de jubilados norte europeos que, gracias al diferencial de renta que obtienen por el desfase que aún persiste entre el coste de la vida en España y en los países más ricos de la Unión Europea, pueden acceder a una vivienda de calidad y mantener un estilo de vida bastante parecido al turístico. También se aprecia con importancia creciente la existencia de un grupo de ciudadanos que residen en la Costa Blanca pero mantienen una vida laboral activa en sus países de origen.

Los datos que se exponen en este apartado forman parte de los resultados de una encuesta llevada a cabo por un equipo de investigación de la Universidad de Alicante (3) cuyo objetivo general era establecer el perfil de los residentes europeos en la provincia de Alicante. Se trata de un sondeo realizado a la población extranjera de la Unión Europea en situación laboral no activa, de ambos sexos, de 18 años y más, alojada en viviendas particulares en la provincia de Alicante. El tamaño muestral es de 872 entrevistas y se realizó por muestro proporcional polietápico en 12 municipios con selección de las unidades últimas por rutas aleatorias. El error muestral obtenido es de +/$5 \%$ para un nivel de confianza del $95,5 \%(P=Q=50)$. El trabajo de campo se llevó a cabo entre diciembre de 2004 y marzo de 2005. Los cuestionarios se aplicaron en español, inglés, francés y alemán mediante entrevista personal en los hogares. Uno de los resultados más relevantes es que se puede establecer que el tipo de "turista residencial" predominante es el que se ha denominado "residente permanente" (propietario de vivienda registrado oficialmente), ya que alcanza al 61,7\% de la población objetivo, mientras que el tipo "turista estacional" (no propietario ni registrado oficialmente) apenas supera una décima parte de los entrevistados (10,3\%). Los otros dos tipos identificados, "residente temporal" (no propietario pero registrado) y "propietario de segunda residencia" alcanzan los porcentajes de 6,2 y 21,7\% respectivamente. Se puede así afirmar que se ha pasado de un modelo de naturaleza eminentemente turística a un modelo migratorio. $\mathrm{Si}$ 
obviamos el hecho de que una parte importante de esta población no se registra, porque no tiene obligación legal de hacerlo como ciudadanos de la Unión Europea, y tomamos los datos oficiales de empadronados, encontramos que el 10,8\% del total de los habitantes de la Costa Blanca son "residentes europeos". Esta presencia de extranjeros supone que en 15 municipios de la provincia la población censada extranjera sea superior a la española (por ejemplo en San Fulgencio, con un $73,9 \%$ de extranjeros (4)) (INE; 2006).

La prueba de que se ha perdido la esencia turística, en el sentido de temporalidad breve del hecho turístico, es que un gran número de estas personas no conserva su vivienda en origen (ver la tabla 1).

\section{Tabla 1}

Empadronamiento, tenencia de vivienda y vivienda en origen

\begin{tabular}{|c|c|c|c|c|}
\hline & \multicolumn{4}{|c|}{ Mantiene casa en su país de origen( \%) } \\
\hline & & Tenencia de la vivienda & Sí & No \\
\hline \multirow{4}{*}{ 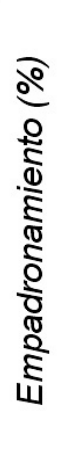 } & \multirow{2}{*}{ Sí } & $\begin{array}{l}\text { Propiedad } \\
\text { Residentes permanentes }\end{array}$ & 23,8 & 76,2 \\
\hline & & $\begin{array}{l}\text { Multipropiedad, alquiler o amigos } \\
\text { Residentes temporales }\end{array}$ & 43,4 & 56,6 \\
\hline & \multirow{2}{*}{ No } & $\begin{array}{l}\text { Propiedad } \\
\text { Propietarios de vivienda secundaria }\end{array}$ & 60,9 & 39,1 \\
\hline & & $\begin{array}{l}\text { Multipropiedad, alquiler o amigos } \\
\text { Turistas estacionales }\end{array}$ & 76,1 & 23,9 \\
\hline
\end{tabular}

Sí empadronado: $x^{2}=9,754 ; \mathrm{p}=0,002$

No empadronado: $x^{2}=6,166 ; \mathrm{p}=0,013$ Fuente: Elaboración propia a partir de la encuesta. P3.- ¿Está empadronado en este municipio? P23.- Su vivienda es: (propiedad; Multipropiedad, alquilada; familia / amigos) P31.- ¿Mantiene una casa en su país de origen? 
Las características y servicios de la Costa Blanca más valorados por los turistas residenciales son los que se presentan en el cuadro 1 :

\begin{tabular}{|l|l|}
\hline Dimensión & Variable \\
\hline Calidad de vida & $\begin{array}{l}\text { - Clima } \\
\text { - Paisaje } \\
\text { - Servicios } \\
\text { - Seguridad } \\
\text { - Atención sanitaria }\end{array}$ \\
\hline Ambiente social agradable & $\begin{array}{l}\text { - Comunidades de compatriotas } \\
\text { - Hospitalidad de los autóctonos }\end{array}$ \\
\hline $\begin{array}{l}\text { Buenas comunicaciones con los } \\
\text { lugares de origen }\end{array}$ & $\begin{array}{l}\text { - Cercanía a aeropuertos y } \\
\text { compañías aéreas "de bajo coste" } \\
\text { - Grandes vías de circulación } \\
\text { (autopistas) }\end{array}$ \\
\hline Nivel de precios & $\begin{array}{l}\text { • Coste de la vida } \\
\text { - Precio de la vivienda }\end{array}$ \\
\hline Conjuntos urbanísticos unitarios & $\begin{array}{l}\text { • Urbanizaciones de calidad con } \\
\text { servicios }\end{array}$ \\
\hline
\end{tabular}

\section{Cuadro 1}

Características percibidas de la Costa Blanca

Fuente: Encuesta de elaboración propia

Tienen especial importancia el clima, el paisaje y determinados servicios públicos, como la seguridad, las comunicaciones, el transporte, la atención sanitaria y la limpieza. También es importante señalar otros dos factores que, sin ser servicios públicos en sí mismos, se encuentran en buena medida en la esfera de lo público, son la tranquilidad y la calidad medioambiental, ambas, por lo general, afectadas muy negativamente por las grandes concentraciones turísticas de los espacios litorales. La calidad medioambiental está cobrando cada día una mayor relevancia, hasta el punto de convertirse en un factor determinante para ciertos segmentos de población a la hora de decidirse por un destino turístico. Esta calidad medioambiental no solamente se ha 
de considerar desde la perspectiva de lo público, también desde el punto de vista de lo privado, jugando en ella un papel fundamental las condiciones ecológicas de la vivienda, así como de la propia urbanización y del espacio que la circunda.

Se ha podido constatar que el turista residencial valora muy positivamente la posibilidad de rodearse de otras familias de su mismo origen y características socioculturales (O'Reilly, 2000; Gustafson, 2002; Huete, 2005). De esta forma, no debe extrañar que se conformen unidades residenciales bastante homogéneas en cuanto a su nacionalidad o área cultural, renta, edad, aficiones, etc. Igualmente, suelen preferir lugares en los que se faciliten estas relaciones, tanto por las propias estructuras urbanas -como pueden ser las salas de reuniones, paseos públicos, lugares de encuentro, etc.-, como por la existencia de asociaciones o instituciones claramente orientadas a estos fines (Simó y Herzog; 2005).

En líneas generales, los turistas residenciales continúan manteniendo vínculos con sus lugares de procedencia, o incluso pueden seguir residiendo en ellos de forma temporal, sobre todo en los periodos estivales. Es lógico, no se produce una ruptura total y continúan teniendo lazos allí donde, por lo general, tienen o han tenido relaciones laborales, familiares y de amistad. Por estas razones aprecian localizaciones que se encuentren bien comunicadas, valorando muy positivamente la cercanía a aeropuertos y las grandes vías de circulación. La implantación de las compañías aéreas de precios bajos ("low cost") en las regiones españolas en las que el turismo residencial tiene más importancia es, a la vez, causa y efecto de este fenómeno, puesto que los turistas residenciales son un segmento de demanda muy importante para estas compañías, pero paralelamente las promociones turístico-residenciales surgen allí donde las comunicaciones son buenas y, en este caso, además, baratas.

El nivel de precios también se constituye en una variable que influye en la decisión de la compra de la vivienda secundaria, aunque quizá menos importante de lo que a priori se podría pensar. Hay que partir de que la influencia de este factor va a depender, primero, de la franja de rentas en la que se sitúa el turista residencial y, en segundo lugar, en la diferencia del nivel de precios entre el lugar de origen y el lugar donde van a situar la nueva vinculación residencial. Los gastos 
del turista residencial en la localidad de destino son importantes. En primer lugar, se encuentra el gasto que han de realizar en la adquisición del inmueble. Este desembolso suele tener unas importantes repercusiones directas sobre el sector de la construcción. También hay que tener en cuenta que buena parte del gasto de estas personas se realiza en los mismos establecimientos frecuentados por la población autóctona del destino turístico, como supermercados, grandes superficies comerciales, panaderías, servicios personales, farmacias y comercio en general.

La mayoría de las personas que se plantean la posibilidad de trasladarse a una zona turística o cercana a ella superan los 50 años de edad, aunque últimamente el abanico se está abriendo a edades más jóvenes. La media de edad se sitúa en los 62,6 años. Esta característica condiciona también sus necesidades, tanto del espacio residencial que eligen como del destino donde está ubicado y también las actividades de ocio que demanda. Todas estas personas suelen tener bastante tiempo libre por estar jubilados, no realizar un trabajo remunerado (amas de casa) o desempeñar una profesión que les permite disponer y distribuir su propio tiempo. Precisamente, en esta circunstancia se encuentra la razón de que se planteen la posibilidad de trasladar su residencia, de un modo total o parcial, a otro lugar de mejor calidad de vida y con más oportunidades de disfrutar de ese tiempo libre del que disponen. 


\section{LOS IMPACTOS DEL TURISMO RESIDENCIAL}

Como impactos económicos de implantación del turismo residencial, cabe señalar, en primer lugar, la revalorización del suelo. Se trata de un efecto que se produce ante cualquier proceso de urbanización, pero que en el caso del turismo residencial adquiere una relevancia e intensidad especial. Podría pensarse que los principales beneficiarios de esta revalorización del suelo son los propietarios de terrenos o zonas rústicas que se transforman en suelo urbanizable, pero no siempre es así. Suelen existir agentes, nativos, foráneos y mixtos, que se adelantan a las expectativas adquiriendo fincas, o más frecuentemente estableciendo opciones de compra de potencial uso residencial. Estas reservas de suelo, cuya evolución depende directamente del ritmo al que aumente la demanda, suelen ser objeto de transacción (muchas veces en varias ocasiones) en función de los cambios de las expectativas, por grupos en buena parte ajenos a los intereses locales, encareciendo de este modo el precio final del producto, principalmente el bien inmobiliario para uso del turista residencial (pero que termina afectando también a los demás habitantes de la zona). De esta manera, la revalorización del suelo, consustancial a los procesos de expansión urbana, aumenta notoriamente en proporción a las expectativas de incremento de la demanda turística. En estos procesos la intervención de los agentes locales suele darse en las primeras etapas.

En segundo lugar se encuentra la construcción de inmuebles. Es evidente que los efectos directos de la construcción sobre la renta y el empleo, tanto por parte de las viviendas residenciales como de la obra civil, son muy elevados y vinculados en su mayor parte a la población local y su entorno directo de influencia. También ocurre algo similar con los efectos indirectos sobre la industria y los servicios auxiliares de la construcción. La promoción y venta del parque de viviendas edificado suele llevarse a cabo por empresas, en unos casos constituidas para este fin por las propias empresas constructoras, en otros como mero producto intermediado mediante compañías inmobiliarias especializadas, normalmente ubicadas en las zonas de origen de los potenciales turistas. Los beneficios derivados de la comercialización y venta de inmuebles residenciales para la economía local suelen ser escasos, dependiendo del grado de integración vertical de las empresas constructoras con las intermediarias y de venta final, ya que es habitual que los beneficios de la intermediación reviertan sobre agentes vinculados a la zona de origen de los turistas compradores. Esta situación se produce generalmente en los destinos turísticos 
emergentes. En este sentido, la asociación de promotores inmobiliarios más importante de la provincia de Alicante alienta ya a sus empresas asociadas a invertir en proyectos de perfil turístico residencial en áreas emergentes como México, Brasil o Croacia (5).

Entre el conjunto de las repercusiones hay que señalar particularmente las que se producen sobre las finanzas locales, debido a la importante generación de rentas públicas que el turismo residencial lleva aparejado. Es más, en multitud de ocasiones el turismo residencial llega a convertirse en un componente estructural de las haciendas locales de los municipios afectados. No hay que insistir en la tradicional debilidad de las arcas municipales y su cada vez mayor responsabilidad en el ámbito de la atención social, al menos en el caso español. Tradicionalmente este hecho ha llevado a las autoridades locales a tener que basar su política financiera en la urbanización, más concretamente en las licencias de construcción y en la venta de la cesión de aprovechamientos medios.

En cuanto a los gastos de instalación que afectan al turismo residencial, se refieren a la necesidad de adquirir una serie de bienes y servicios para acondicionar los inmuebles, por ejemplo: el alta en el suministro de energía eléctrica, las comunicaciones, el abastecimiento de agua y todos los equipamientos del hogar. Es evidente, que estos gastos, como en el caso de la construcción, favorecen directamente al comercio y la industria del municipio y de su zona de influencia. Los gastos que los turistas residenciales realizan en el destino se constituyen en un importante factor de estímulo y desarrollo para la economía local. 


\begin{tabular}{|c|l|}
\cline { 2 - 3 } Cuadro 2 & • Gastos turísticos y de ocio \\
- Gastos residenciales (alimentación, servicios al hogar, servicios a las \\
del turismo residencial & personas) \\
- Creación de empleo, tanto directo como indirecto e inducido \\
- Apertura y mantenimiento de cuentas bancarias \\
• Importante aportación tributaria \\
• Mantenimiento de servicios profesionales (arquitectos, abogados, \\
agencias de intermediación inmobiliaria, aparejadores, economistas, \\
notarios, registradores, etc.) \\
- Incidencia en la creación de servicios empresariales, restaurantes, \\
bares, cafeterías, comercios, ocio, etc. \\
• Nuevas orientaciones económicas en la localidad distintas a las \\
tradicionales \\
• Diversificación productiva con un mayor dinamismo empresarial y \\
económico \\
\hline
\end{tabular}

Fuente: Elaboración propia

Efectivamente, hay toda una serie de gastos en los que los turistas residenciales incurren y que comprenden los gastos de traslado, de manutención, y los de ocio y diversión. Por otro lado, hay que contar con los gastos propiamente residenciales, es decir, todos aquellos referidos al mantenimiento y conservación del inmueble, transportes, y los servicios personales y del hogar. Es precisamente en estos últimos, donde el turista residencial se separa más del modelo de consumo del residente medio de la localidad: es frecuente que contrate servicios de asistencia para el hogar, jardinería, catering, asesores fiscales, administradores, seguridad, etc. De hecho, en los destinos turísticos con fuerte implantación residencial, han surgido empresas especializadas en este tipo de servicios que hasta ahora se prestaban desde la economía informal y sumergida. Cuando la vivienda es en propiedad, también inciden sobre ella impuestos y tasas locales correspondientes que benefician la economía de los ayuntamientos. 
Además, la demanda del turismo residencial suele tener un efecto desestacionalizador, especialmente en actividades como la restauración y las actividades de ocio activo y cultural, manteniendo, en muchos casos, empleos que de otra manera, hubieran desaparecido pasando a engrosar el paro estacional. En este sentido, son muchas las actividades que pueden demandar los turistas residenciales $y$, consecuentemente, se precisará desarrollar cierto tipo de empresas, tanto públicas como privadas, que van a jugar un papel vital en el incremento de los empleos locales. Cabe destacar el impulso económico que puede ocasionar en una localidad las actividades de ocio, tiempo libre y calidad de vida. En líneas generales, el impulso y desarrollo de la oferta de ocio suele provenir de la iniciativa privada $y$, dentro de ella de la pequeña y mediana empresa. Además, las empresas y agentes del sector tratan de abarcar todas las áreas del ocio, integrando en su oferta un gran número de actividades de las diferentes áreas. Para ello se subcontratan pequeñas empresas especializadas o se producen acuerdos de colaboración entre empresas y profesionales.

\begin{tabular}{|l|l|}
\hline Entidad & Actividad \\
\hline Centros culturales & $\begin{array}{l}\text { - Actividades lúdico-culturales: dibujo, pintura, } \\
\text { artesanía, restauración, idiomas, estética, de la } \\
\text { naturaleza } \\
\text { - Actividades físicas: gimnasia, aeróbic, yoga, } \\
\text { tai-chi, bailes de salón... } \\
\text { • Organización de excursiones, acampadas y } \\
\text { otras actividades al aire libre } \\
\text { - Espacios para encuentro de población } \\
\text { específica: ludotecas, clubes de tercera edad, } \\
\text { para asociaciones... }\end{array}$ \\
\hline $\begin{array}{l}\text { Organismos públicos } \\
\text { implicados en la oferta } \\
\text { de ocio }\end{array}$ & $\begin{array}{l}\text { - Organización de eventos y espectáculos } \\
\text { culturales, recreativos y deportivos } \\
\text { • Organización y/o subvención y promoción } \\
\text { de actividades de carácter ludico-cultural } \\
\text { y deportivo en espacios naturales o } \\
\text { instalaciones específicas }\end{array}$ \\
\hline
\end{tabular}

\section{Cuadro 3}

Generación de nuevas actividades económicas del turismo residencial 


\begin{tabular}{|c|c|}
\hline $\begin{array}{l}\text { Centros asistenciales para } \\
\text { personas mayores }\end{array}$ & $\begin{array}{l}\text { - Estimulación de habilidades cognitivas } \\
\text { (juegos y ejercicios de memoria, cálculo...), } \\
\text { motrices (gimnasia pasiva, masajes, bailes con } \\
\text { pañuelo, juego con bolos...) y sociales (teatro, } \\
\text { juegos participativos, de mesa...) } \\
\text { - Fisioterapia, terapia ocupacional } \\
\text { - Excursiones/viajes } \\
\text { - Atención médica } \\
\text { - Hostelería } \\
\text { - Bibliotecas }\end{array}$ \\
\hline $\begin{array}{l}\text { Profesionales y empresas } \\
\text { de tiempo libre, turismo } \\
\text { activo, deportes de } \\
\text { aventura, naturaleza }\end{array}$ & $\begin{array}{l}\text { - Actividades en el medio natural: } \\
\text { rutas turísticas, senderismo, talleres } \\
\text { medioambientales, senderismo, rutas a caballo, } \\
\text { agroturismo, acampada } \\
\text { - Organización de otras de carácter lúdico- } \\
\text { cultural: talleres, campamentos, campos } \\
\text { de trabajo, itinerarios paisajísticos o } \\
\text { monumentales, exposiciones }\end{array}$ \\
\hline $\begin{array}{l}\text { Empresas y entidades de } \\
\text { deportes }\end{array}$ & $\begin{array}{l}\text { - Oferta complementaria de animación, } \\
\text { programas de salud y belleza, yoga y } \\
\text { relajación, observación telescópica, } \\
\text { excursiones a caballo, senderismo, tiro con } \\
\text { arco... }\end{array}$ \\
\hline $\begin{array}{l}\text { Empresas de } \\
\text { comunicación }\end{array}$ & $\begin{array}{l}\text { - Prensa especialmente dirigida al residente } \\
\text { extranjero } \\
\text { - Agencias de publicidad }\end{array}$ \\
\hline
\end{tabular}

Fuente: Encuesta de elaboración propia

El beneficio evidente que el turismo residencial ha supuesto para la economía de la provincia de Alicante se ve acompañado por otros efectos de arrastre más negativos, entre los que destacan las transformaciones en las estructuras sociodemográficas de muchas localidades a partir de la doble inmigración de, por un lado, mano de obra joven atraída por el mercado laboral y, por otro, de un intenso flujo de extranjeros de edad avanzada que fijan su residencia durante varios meses al año en el nuevo enclave turístico, dando lugar a un progresivo envejecimiento de la estructura poblacional y, en consecuencia, a la exigencia, por parte de la ciudadanía, de una serie de servicios e infraestructuras básicas no previstas y cuya planificación resulta complicada 
debido al carácter inestable de una población flotante que resulta muy difícil cuantificar. Esta problemática situación se agudiza al ser frecuente la localización de estos nuevos semi-residentes en urbanizaciones aisladas del núcleo urbano.

Los impactos más negativos se concentran en la esfera medioambiental y se derivan de la actividad urbanística asociada al turismo. En este sentido han de apuntarse tres esenciales: la ocupación urbanística de un territorio limitado, la sobreexplotación de unos recursos hídricos escasos y la destrucción irreparable de entornos naturales de incalculable riqueza.

Otros impactos son los que se relacionan con procesos agresivos de aculturación (pérdida de la identidad cultural local) y, muy especialmente, la concesión de un margen excesivo a las prácticas especulativas llevadas a cabo por los promotores inmobiliarios. Por lo que respecta a su capacidad para crear riqueza, el turismo residencial genera, en términos relativos, menor empleo que el modelo tradicional centrado en la oferta hotelera y, de hecho, una parte considerable del empleo se integra en sectores, empresas y actividades ya existentes y que habitualmente atienden las demandas de los residentes. De este modo, su capacidad de crear puestos de trabajo se confunde con la que genera la demanda de la población local. 


\section{A MODO DE CONCLUSIÓN: tendencias del turismo residencial y propuestas desde la experiencia de la Costa Blanca}

En un periodo con crecimiento económico moderado pero continuado, como parecen haber entrado los principales países occidentales, existe un notorio incremento de la demanda turística en cualquiera de sus múltiples facetas y, entre ellas, el modelo turístico residencial (ICEX; 2003). Al mismo tiempo, el notable aumento de la edad media de la población demandante y un comprobado aumento de sus rentas disponibles, a causa del vencimiento de sus anteriores hipotecas (así como por la liberación de otros gastos familiares), a lo que se ha unido también unos bajos tipos de interés bancario, ha disparado la demanda de la tipología turística residencial, con especial incidencia en países como España, debido a su climatología y localización cercana a los principales focos emisores turísticos del norte y del centro de Europa.

\begin{tabular}{|c|c|c|}
\hline Cuadro 4 & Tendencia social & $\begin{array}{l}\text { Consecuencia para el turismo } \\
\text { residencial }\end{array}$ \\
\hline \multirow[t]{4}{*}{$\begin{array}{r}\text { Tendencias del turismo } \\
\text { residencial }\end{array}$} & $\begin{array}{l}\text { - Ampliación de segmentos de } \\
\text { demanda con gran capacidad de } \\
\text { gasto: entre } 45 \text { y } 55 \text { años }\end{array}$ & $\begin{array}{l}\text { - Aumento intenso de las segundas } \\
\text { residencias } \\
\text { - Viviendas de tipo unifamiliar }\end{array}$ \\
\hline & $\begin{array}{l}\text { - Globalización de la economía } \\
\text { - Coyuntura económica favorable } \\
\text { - Estabilidad de los tipos de cambio } \\
\text { - Mejoras en las infraestructuras y } \\
\text { medios de transporte }\end{array}$ & $\begin{array}{l}\text { - Aumento de la demanda } \\
\text { - Ampliación de los destinos } \\
\text { competidores }\end{array}$ \\
\hline & $\begin{array}{l}\text { - Mejoras en los sistemas de } \\
\text { información y comunicación } \\
\text { - Consolidación del teletrabajo } \\
\text { - Abaratamiento del transporte y } \\
\text { desarrollo de compañías aéreas de } \\
\text { bajo coste }\end{array}$ & $\begin{array}{l}\text { - Cualificación del producto turístico } \\
\text { que se ha de ofertar } \\
\text { - Ampliación y flexibilización de los } \\
\text { mercados turísticos }\end{array}$ \\
\hline & $\begin{array}{l}\text { - Mejora de la calidad de vida } \\
\text { - Alargamiento de la esperanza de } \\
\text { vida } \\
\text { - Se dispone de más tiempo } \\
\text { libre: jornada laboral reducida y } \\
\text { jubilación anticipada }\end{array}$ & $\begin{array}{l}\text { - Aumento de la demanda } \\
\text { residencial }\end{array}$ \\
\hline
\end{tabular}




\begin{tabular}{|c|l|}
\hline $\begin{array}{c}\text { - El turista exige mayor calidad a } \\
\text { todos los niveles: }\end{array}$ & $\begin{array}{l}\text { - Cualificación del producto turístico } \\
\text { y del destino } \\
\text { - Mejores instalaciones }\end{array}$ \\
- Mejores servicios & $\begin{array}{l}\text { Búsqueda de destinos en zonas no } \\
\text { saturadas }\end{array}$ \\
\hline
\end{tabular}

Fuente: Elaboración propia a partir de Torres Bernier; 2003

Por otra parte, la tendencia a la globalización y el propio proceso de unificación europea, con una única moneda que facilita las transacciones comerciales y turísticas, han influido también considerablemente en el incremento de la oferta de este tipo de residencias, con el consiguiente aumento de la competencia. En los 90 se intensificó un proceso que se venía gestando desde años antes: el progresivo poblamiento de las costas e islas mediterráneas por ciudadanos norte europeos durante periodos cada vez más largos. El fenómeno localiza un momento crucial en 1993, cuando la legislación europea elimina las trabas a los ciudadanos de la Unión para comprar propiedades en el espacio común. Por otro lado, el auge del mercado inmobiliario en el sur de Europa contrasta con la depresión del mismo en el norte desde principios de los años 80 . El alza de precios de las propiedades inmobiliarias en el norte de Europa trasladó el interés de los compradores hacia los nuevos mercados del sur. Este acontecimiento concentra definitivamente el proceso turístico residencial en el Mediterráneo occidental. Aunque los contrastes económicos entre el norte, el centro y el sur de Europa se han atenuado en los últimos años, las diferencias, no obstante, siguen siendo importantes. Entonces, la tendencia apunta a un ciclo en el que aumentará el número de europeos que van a optar por la compra de una vivienda turística en aquellos enclaves mediterráneos que identifican como más atractivos para sus intereses vitales.

Existe una percepción generalizada entre los europeos de que es preciso recuperar valores y hábitos perdidos como consecuencia del progreso, marcado por el consumismo, por el alejamiento de la naturaleza y por la adquisición de hábitos nocivos para la salud. Por ello se está intensificando la demanda en torno a servicios que favorecen el aumento del bienestar personal y se han incorporado al mercado numerosas empresas y profesionales dando respuesta a las demandas que surgen de dichas carencias y de las que el turismo residencial es un buen ejemplo, por englobar a colectivos de ciudadanos altamente preocupados por alcanzar unas mayores cuotas de bienestar y de calidad de vida. 
El turismo residencial como modelo de desarrollo cuya demanda está formada por personas con gran disponibilidad de tiempo libre y rentas altas, que pretenden la mejora de su calidad de vida al adquirir una vivienda turística, puede ofrecer buenas oportunidades de creación de empresas y de desarrollo social y económico. Este escenario será posible siempre y cuando se atienda a criterios de sustentabilidad y no a un uso abusivo de la construcción con la consiguiente degradación medioambiental. A partir de la experiencia en la Costa Blanca, nos atrevemos a proponer algunas cuestiones a considerar, partiendo de la base de que se requiere un importante esfuerzo en la configuración de estrategias de ordenación y planificación del territorio. En un destino emergente será necesario que el modelo se desarrolle manteniendo un equilibrio entre la oferta hotelera y la oferta puramente residencial. Por otra parte, es imprescindible preservar la calidad de las edificaciones y realizar los proyectos residenciales con criterios de sustentabilidad en cuanto al uso de los recursos naturales, las densidades de edificación y una estética que siga los gustos tradicionales del lugar. En este sentido, se puede prever que la variable más determinante del negocio turístico en los próximos años será la diversificación y diferenciación de los destinos, por lo que el destino turístico-residencial habrá de ser capaz de diferenciarse basándose en la propia idiosincrasia del lugar, puesto que la calidad, en el sentido del acceso a los servicios e infraestructuras que la demanda exige, se da ya por supuesta. 


\section{BIBLIOGRAFÍA}

- Gustafson, Per (2002). "Turismo y movimientos migratorios estacionales de personas jubiladas" en Annals of Tourism Research en Español. 4 (2): 337-359

- Hall, C. Michael y Müller, Dieter K. (2004) Tourism, mobility and second homes: between elite landscape and common ground. Clevedon: Channel View Books.

- Hiernaux-Nicolas, Daniel (2005) "La promoción inmobiliaria y el turismo residencial: el caso mexicano" en Scripta Nova, Revista electrónica de Ciencias Sociales. Universidad de Barcelona. vol. IX, núm. 194 (05).

- Huete, Raquel (2005) "Factores de atracción de Alicante como destino residencial: el punto de vista de los residentes europeos" en Mazón, Tomás y Aledo, Antonio (Eds.) Turismo residencial y cambio social. Nuevas perspectivas teóricas y empíricas. Alicante: Editorial Aguaclara.

- Instituto de Comercio Exterior (ICEX) (2003). Turismo residencial español. Diagnóstico y propuestas de internacionalización. Madrid: ICEX.

- Instituto Nacional de Estadística de España (INE) (2001). Censos de vivienda y población 2001. Resultados definitivos <http://www.ine.es> consultado el 15 de mayo de 2007.

<http://www.ine.es > consultado el 15 de mayo de 2007.

- Mazón, Tomás y Aledo, Antonio (Eds.) (2005). Turismo residencial y cambio social. Nuevas perspectivas teóricas y empíricas. Alicante: Editorial Aguaclara.

- Mazón, Tomás y Huete, Raquel (2005). "Turismo residencial en el litoral alicantino: los casos de Denia, Altea, Benidorm, Santa Pola y Torrevieja" en Mazón, Tomás y Aledo, Antonio (Eds.) Turismo residencial y cambio social. Nuevas perspectivas teóricas y empíricas. Alicante: Editorial Aguaclara.

- O'Reilly, Karen (2000). The British on the Costa del Sol. Transnational identities and local communities. Londres: Routledge.

- Raya Mellado, Pedro (Dir.) (2001). Turismo residencial en Andalucía. Sevilla: Consejería de Turismo y Deportes de la Junta de Andalucía.

- Salvà, Pere (2005). "Procesos, pautas y tendencias del turismo residencial en las Islas Baleares: żinmigrantes de lujo o turistas de larga estancia?" en Mazón, Tomás y Aledo, Antonio (Eds.) Turismo residencial y cambio social. Nuevas perspectivas teóricas y empíricas. Alicante: Editorial Aguaclara. 
- Simó, Carles y Herzog, Beno (2005). "El asociacionismo de los residentes europeos en la Comunidad Valenciana" en Mazón, Tomás y Aledo, Antonio (Eds.) Turismo residencial y cambio social. Nuevas perspectivas teóricas y empíricas. Alicante: Editorial Aguaclara.

- Torres Bernier, Enrique (2003). "El turismo residenciado y sus efectos en los destinos turísticos" en Estudios Turísticos. 155-156: 45-70.

- Vera Rebollo, José Fernando y Monfort Mir, Vicente (1994) "Agotamiento de modelos turísticos clásicos. Una estrategia territorial para la cualificación: la experiencia de la Comunidad Valenciana" en Estudios Turísticos, n. 123, pp. 17-45.

- Zapata, Vicente (2002). La inmigración extranjera en Tenerife. Santa Cruz de Tenerife: Cabildo Insular de Tenerife. 


\section{NOTAS}

(1) Vivienda secundaria es aquella usada sólo en vacaciones, fines de semana, trabajos temporales, etc. en contraposición con la vivienda principal que constituye residencia habitual de al menos una persona.

(2) España está dividida jurídico-administrativamente en 50 provincias, que integran 17 comunidades autónomas. La Comunidad Valenciana está formada por tres provincias: Castellón, Valencia y Alicante.

(3) El grupo de "Estudios de desarrollo turístico" es un equipo de investigación de la Universidad de Alicante, dirigido por el Dr. Tomás Mazón, al que pertenecen los autores de este trabajo. La encuesta se realizó dentro del Proyecto de Investigación "El turismo residencial extranjero en la provincia de Alicante (GV04B/558)" financiado por la Consellería de Empresa, Universidad y Ciencia de la Generalitat Valenciana.

(4) El 20,14\% de la población de la provincia de Alicante es de nacionalidad extranjera, un total de 359.150 personas. Esta cifra supone el mayor porcentaje de todas las provincias españolas y más del doble de la media española (9,27\% de extranjeros).

(5) "Provia anima a los promotores a invertir en el Caribe y Europa" Diario Información de Alicante. 27 de mayo de 2007. 


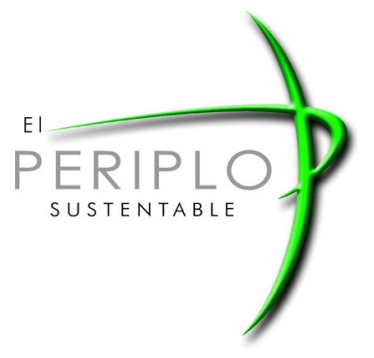

FICHA BIBLIOGRAFICA:

Huete-Nieves, R. Tendencias del turismo residencial: El caso del Mediterráneo Español.

El Periplo Sustentable. Espacio de análisis y reflexión sobre Turismo Sustentable. México: Universidad Autónoma del Estado de México, julio de 2008, núm. 14

$<$ http://www.uaemex.mx/plin/psus/rev14/articulo_04.pdfs.

[ISSN: 1870-9036]. 